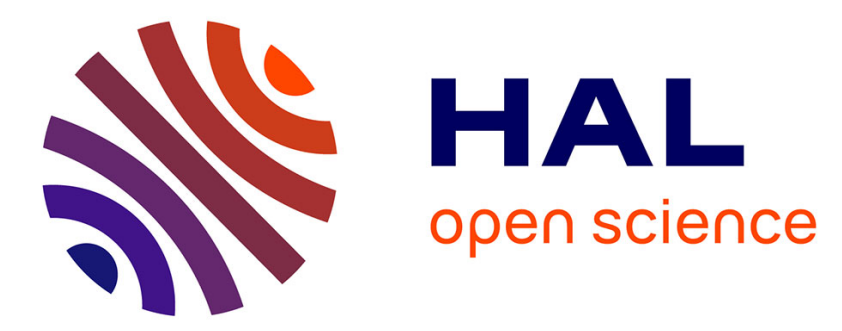

\title{
Numerical modeling of thermal desorption mass spectroscopy (TDS) for the study of hydrogen diffusion and trapping interactions in metals
}

Caitlin Hurley, Frantz Martin, Loic Marchetti, Jacques Chêne, Christine Blanc, Eric Andrieu

\section{To cite this version:}

Caitlin Hurley, Frantz Martin, Loic Marchetti, Jacques Chêne, Christine Blanc, et al.. Numerical modeling of thermal desorption mass spectroscopy (TDS) for the study of hydrogen diffusion and trapping interactions in metals. International Journal of Hydrogen Energy, 2015, 40 (8), pp.34023414. 10.1016/j.ijhydene.2015.01.001 . hal-01480522

\section{HAL Id: hal-01480522 \\ https://hal.science/hal-01480522}

Submitted on 1 Mar 2017

HAL is a multi-disciplinary open access archive for the deposit and dissemination of scientific research documents, whether they are published or not. The documents may come from teaching and research institutions in France or abroad, or from public or private research centers.
L'archive ouverte pluridisciplinaire HAL, est destinée au dépôt et à la diffusion de documents scientifiques de niveau recherche, publiés ou non, émanant des établissements d'enseignement et de recherche français ou étrangers, des laboratoires publics ou privés. 


\section{OATAO \\ Open Archive Toulouse Archive Ouverte}

\section{Open Archive TOULOUSE Archive Ouverte (OATAO)}

OATAO is an open access repository that collects the work of Toulouse researchers and makes it freely available over the web where possible.

This is an author-deposited version published in : http://oatao.univ-toulouse.fr/ Eprints ID : 16705

To link to this article : DOI:10.1016/j.ijhydene.2015.01.001

URL : http://dx.doi.org/10.1016/j.ijhydene.2015.01.001

To cite this version : Hurley, Caitlin and Martin, Frantz and Marchetti, Loïc and Chêne, Jacques and Blanc, Christine and Andrieu, Eric Numerical modeling of thermal desorption mass spectroscopy (TDS) for the study of hydrogen diffusion and trapping interactions in metals. (2015) International Journal of Hydrogen Energy, vol. $40\left(\mathrm{n}^{\circ}\right.$ 8). pp. 3402-3414. ISSN 0360-3199

Any correspondence concerning this service should be sent to the repository administrator: staff-oatao@listes-diff.inp-toulouse.fr 


\title{
Numerical modeling of thermal desorption mass spectroscopy (TDS) for the study of hydrogen diffusion and trapping interactions in metals
}

\author{
Caitlin Hurley ${ }^{a, b}$, Frantz Martin ${ }^{a, *}$, Loïc Marchetti ${ }^{a, c}$, Jacques Chêne ${ }^{d}$, \\ Christine Blanc ${ }^{b}$, Eric Andrieu ${ }^{b}$ \\ ${ }^{a}$ CEA, DEN, DPC, SCCME, Laboratoire d'Étude de la Corrosion Aqueuse, F-91191 Gif-sur-Yvette, France \\ ${ }^{\mathrm{b}}$ Université de Toulouse, Institut Carnot CIRIMAT, UPS/INPT/CNRS, ENSIACET, 4 allée Emile Monso, \\ 31030 Toulouse Cedex 4, France \\ ' DEN, MAR, DTCD, SECM, Laboratoire d'Etudes du Comportement à Long Terme de matériaux de conditionnement, \\ CEA Marcoule, 30207 Bagnols sur Céze, France \\ ${ }^{\mathrm{d}}$ CNRS/CEA UMR 8587, CEA Saclay, 91191 Gif-sur-Yvette, France
}

Keywords:

Diffusion

Hydrogen

Hydrogen embrittlement

Numerical modeling

Thermal desorption mass spectros-

copy

Trapping

\begin{abstract}
A B S T R A C T
Deriving the kinetic reaction constants associated with hydrogen diffusion and trapping in metals from thermal desorption mass spectroscopy (TDS) spectra proves to be complicated and the existing analysis methods are subject to debate. This article will provide a brief background of several commonly employed analysis techniques and discuss the necessity of a more complex and rigorous analysis method for the determination of the kinetic constants associated with hydrogen trapping interactions. Furthermore, a numerical simulation method will be proposed using the McNabb \& Foster equations to fit experimental TDS spectra in order to derive both diffusion and trapping/detrapping parameters, including the respective pre-exponential constants and activation energies associated with these interactions in metals.
\end{abstract}

\section{Introduction}

Hydrogen-material interactions are a subject of very high interest in many fields of research, mainly concerning possible material degradation associated with hydrogen uptake. Absorbed hydrogen can become trapped in the microstructural defects, or trap sites (TS), intrinsically present in the material. These TS may include grain boundaries, precipitates, or defects, such as dislocations, vacancies, and interstitials which can be created during material preparation and/or a working process [1-4]. These defects can interact with hydrogen in the material in different ways creating deformation fields, internal stresses, electronic interactions,

\footnotetext{
* Corresponding author. Tel.: +331690848 86 .

E-mail address: frantz.martin@cea.fr (F. Martin) http://dx.doi.org/10.1016/j.ijhydene.2015.01.001
} 
etc. Trapping interactions can slow the transport of hydrogen and have a negative impact on the materials' mechanical properties which can lead to premature degradation due to hydrogen uptake. Material degradation by hydrogen embrittlement (HE) is a major concern in many industrial materials and is not limited to one industry nor environment [2, 5-9]. To better understand this phenomenon it is necessary to investigate the specific interactions between different types of TS and absorbed $\mathrm{H}$.

Thermal desorption mass spectroscopy (TDS) is a very powerful tool commonly used for studying the diffusion and trapping of hydrogen and its isotopes in metals. This experimental approach generally includes, first, pre-charging a material with hydrogen, then measuring its desorption flux under vacuum or under a constant inert gas flow during a temperature ramp or at an isotherm. Literature states that this experimental analysis can provide important information concerning the total $\mathrm{H}$ concentration in the material, the amount of $\mathrm{H}$ that occupies trap sites, possibly the respective TS density, and eventually the detrapping activation energy associated with the trapping mechanism [10-14], but in order to access this information a spectral analysis technique must be used. Today, spectral analysis proves to be a controversial subject and the reliability and applicability of these techniques needs to be reviewed.

One of the simplest and most commonly used analytical methods was developed by Choo \& Lee [10]. This method uses the Kissinger equation [15], Eq. (1), to assign detrapping activation energies $\left(E_{p}\right)$ to specific TS types.

$\frac{\partial \ln \frac{\phi}{T_{m}^{2}}}{\partial \frac{1}{T_{m}}}=\frac{E_{p}}{R}$

In this equation $\phi$ represents the temperature ramp rate, $T_{m}$ the temperature of maximum desorption flux, and $R$ the ideal gas constant. In this analysis method $\phi$ is varied, which affects the $T_{m}$. The TS detrapping activation energy is then determined from the slope $\left(E_{p} / R\right)$ of the $\ln \frac{\phi}{T_{m}^{2}}$ vs. $1 / T_{m}$ plot, commonly referred to as a "Choo-Lee plot" [10]. One downside to this analysis method is that diffusion is neglected as a spectral contribution, thereby attributing all desorption flux to previously trapped hydrogen.

Some more complicated models analyzing systems in which diffusion and trapping interactions coexist, which will be referred to diffusion-trapping systems or DTS, are based upon the McNabb and Foster equations [13] (Eqs. (2)-(3)).

$\frac{\partial \mu}{\partial t}+n \frac{\partial \theta}{\partial t}=D \frac{\partial^{2} \mu}{\partial x^{2}}$

$\frac{\partial \theta}{\partial t}=k \mu(1-\theta)-p \theta$

In Eqs. (2)-(3), $\mu$ represents the local interstitial hydrogen concentration in molar fraction, $n$ the TS density in terms of moles of traps per unit volume $\left(V_{m}\right), \theta$ the TS fractional occupancy, $t$ represents time, $x$ is the point in the sample being evaluated, $D$ the diffusion coefficient, and $k$ and $p$ the respective trapping and detrapping kinetic constants. A generalized assumption concerning $D, k$, and $p$ is that they all follow an Arrhenius relationship, thereby giving them their temperature dependence as well as an associated activation energy $\left(E_{D}, E_{k}, E_{p}\right)$ and pre-exponential constant $\left(D_{0}, k_{0}, p_{0}\right)$. Furthermore, this set of equations may be modified to take into consideration several TS types through the addition of supplementary trap occupancy terms each with their own respective kinetic reaction equation [12].

As these equations are highly coupled, no analytical solution can be easily found. In order to work with this system two different approaches may be used: (i) determine a set of simplifications allowing for the derivation of an analytical solution or (ii) solve these equations via a numerical model.

Oriani et al. [14] choose to impose a set of hypotheses in order to develop a simplified analytical model. Their assumptions include: (i) one atom of $\mathrm{H}$ per TS, (ii) one type of TS, (iii) local thermodynamic equilibrium between the trapped and interstitial $\mathrm{H}$, and (iv) a highly dilute system. If all these conditions are met an effective diffusion coefficient $\left(D_{\text {eff }}\right)$ can be used. When the assumption of local thermodynamic equilibrium between trapped and interstitial hydrogen is supposed true, the reaction

$\mathrm{H}+[]_{\text {trap }} \underset{p}{\stackrel{k}{\rightleftharpoons}}[\mathrm{H}]_{\text {trap }}$

(where $H$ represents a single hydrogen, [ ] trap a trap site, and $[H]_{\text {trap }}$ a trapped hydrogen, with $k$ and $p$ the respective trapping and detrapping kinetic constants) can no longer be considered a rate limiting step. Although this assumption may be relevant in certain cases (i.e. when $k$ and $p$ are sufficiently high) it excludes, by hypothesis, an analysis of trapping phenomena in terms of kinetic considerations [16,17]. Consequently the respective trapping and detrapping kinetic constants cannot be determined [16]. Despite the fact that diffusion and trapping interactions do not always exist in equilibrium, many researchers base their analysis upon this assumption $[12,14,18,19]$.

Recently some interesting work concerning the simulation of hydrogen permeation experiments in the presence of traps has been published by Svoboda and Fischer et al. [20-23]. In their earlier publication [20], they conclude that numerical modeling of a diffusion and trapping system using $D_{\text {eff }}$ and "Oriani type" simplifications is valid, but in later works they show that $D_{\text {eff }}$ can only be applied to systems with a weak hydrogen concentration gradient and specific combinations of TS density and interstitial $\mathrm{H}$ concentrations (i.e. for relatively simple diffusion and trapping systems) [21,23]. One of the goals of this paper is to present simulations using a general model for diffusion and trapping interactions which is not limited by such hypotheses. For that purpose the McNabb and Foster equations [13] will be used and not a more simplified system such as one using a $D_{\text {eff. }}$.

Mavrikakis et al. [24,25] have numerically explored the simulation of TDS spectra for reaction-diffusion (RD) systems with concentration gradients. In these RD systems, the reaction refers to an absorption or desorption process coupled with molecular recombination on the materials' surface. In these systems, trapping is not considered. Their proposed simulation approach, which takes into account the samples' experimental "history", has been adapted to a DTS through the use of the McNabb and Foster equations [13] by Yagodzinskyy et al. [26]. 
Table 1 - Boundary conditions used in simulation where $L=$ sample thickness, $t_{C h}=$ final charging time, and $t_{T r}=f_{i n a l}$ transfer time.

\begin{tabular}{llll} 
& $\mu[x, t]$ & $\theta[x, t]$ \\
\hline Charging & $\mu[0, t]=\mu_{0}, \mu[\mathrm{L}, \mathrm{t}]=\mu_{0}$ or 0 & $\mu[x, 0]=0$ & $\theta[x, 0]=0$ \\
Transfer & $\mu[0, t]=\mu[\mathrm{L}, \mathrm{t}]=0$ & $\mu[x, 0]=\mu\left[x, \mathrm{t}_{\mathrm{Ch}}\right]$ & $\theta[x, 0]=\theta\left[x, \mathrm{t}_{\mathrm{Ch}}\right]$ \\
TDS & $\mu[0, \mathrm{t}]=\mu[\mathrm{L}, \mathrm{t}]=0$ & $\mu[x, 0]=\mu\left[x, \mathrm{t}_{\mathrm{Tr}}\right]$ & $\theta[x, 0]=\theta\left[x, \mathrm{t}_{\mathrm{Tr}}\right]$ \\
\hline
\end{tabular}

They have used this approach to simulate all experimental steps, including a non-homogeneous charging (which imposes both interstitial and trapped $\mathrm{H}$ concentration gradients in the material) followed by an aging period, and finally TDS analysis. One downside to their technique is that they have used a very large simplifying hypothesis: $H$ retrapping does not occur during TDS analysis. In reality during all experimental steps, trapping from lattice sites to TS can occur freely along with the retrapping of previously trapped $\mathrm{H}$. Using this simplified model they have tried to fit experimental desorption spectra in order to derive the kinetic constants associated with specific TS but some spectral reproduction difficulties were encountered. They have attributed these difficulties to their simplifying hypothesis [26].

In the present paper a numerical approach for the simulation of TDS spectra using a non-dimensional version of the McNabb and Foster equations, Eqs. (2)-(3), taking into account the entire experimental sample history and without imposing some of the traditional simplifying hypotheses (ie. local thermodynamic equilibrium and no retrapping during TDS analysis) will be explored in-depth. The extreme sensitivity of TDS spectra on the sample parameters and experimental conditions along with the importance of considering preexponential constants and activation energies associated for trapping and detrapping during analysis will be discussed. Furthermore, a developed numerical code for diffusiontrapping/detrapping spectral analysis will be presented and discussed in terms of coupling experimental results with numerical simulation.

\section{Mathematical model and simulation approach}

In this study interstitial diffusion and trapping, at one TS, are assumed to be the only rate limiting steps for hydrogen absorption and desorption and therefore the McNabb and Foster equations [13], see Eqs. (2)-(3), can be used to model the system. Surface reaction and recombination are not considered to be rate limiting steps at this point in the model [29]. Eq. (2) is a fickian diffusion equation, that has been modified to include a trap occupancy term, $\theta$, and Eq. (3) is a direct mathematical representation of the kinetic reaction equation for the trapping and detrapping of hydrogen in a trap site, see Eq. (4).

In this model, a dilute system $(\theta \approx 0)$ was not assumed and thereby the $(1-\theta)$ term in Eq. (3) was not neglected, as done by Kasuya et al. [12]. Furthermore, the assumption of local thermodynamic equilibrium between trapped and lattice hydrogen and the use of an effective diffusion coefficient will not be used [14] as this assumption renders the trapping and detrapping rates, reaction rates $k$ and $p$ of Eq. (4), infinite and thereby indeterminable [16].
A uniform and homogeneous distribution of traps is assumed and the sample is considered a finite medium of thickness $L$ and it is assumed that each TS is isolated in the material and that they do not interact directly with one another. A finite difference method was used to solve simultaneously for $\theta$ and $\mu$, respectively the trap occupancy and lattice hydrogen concentration in Eqs. (2), (3). It is imperative to know the $\mathrm{H}$ distribution in the material in order to simulate the system. The simulation has been split into three sequential steps further "mirroring" the entire experimental protocol. This procedure includes: (i) charging the sample in hydrogen for a period of time at a fixed temperature, (ii) transfer from the charging setup to the TDS system (aging at room temperature), and (iii) TDS testing imposing a regulated temperature ramp.

Each simulation step uses the previous' final concentration profiles, for $\mu$ and $\theta$ as its initial concentration profiles, and it has been assumed that there is no hydrogen present in a material before charging. For the charging step (i) the initial surface hydrogen concentration, $\mu_{0}$, at the charged face(s) ( $x=0$ and/or $x=L)$ is assumed to be equal to its solubility in the material and is held constant for the entire charging period. For the latter steps, (ii) transfer and (iii) TDS, the hydrogen concentration at both faces is set to zero and the desorption flux can be calculated, at $x=0$ and $x=L$. It has also been assumed that no absorption takes place during these stages. These boundary conditions can be seen in Table 1 . When simulating TDS spectra, the total desorption flux is considered to be the sum of the desorption from both sample faces $(x=0$ and $x=L)$ as the sample is considered a semiinfinite slab, with a finite thickness.

\section{Experimental parameters}

\section{Initial hydrogen concentration}

As previously mentioned, simulations will be carried out using a non-dimensional version of the McNabb and Foster equations, therefore injecting only a detrapping activation energy is not sufficient for simulations. An extensive literature review has resulted in finding very little information concerning the kinetic constants associated with hydrogen trapping in metals, especially concerning the trapping activation energy $\left(E_{k}\right)$ and the pre-exponential constants $\left(k_{0}\right.$ and $\left.p_{0}\right)$. The only set of complete diffusion and trapping parameters have been reported by Turnbull et al. [27] for 1 TS in a lowcarbon steel/pure iron of thickness $0.2 \mathrm{~cm}$ when imposing a TDS temperature ramp rate $(\phi)$ of $2 \mathrm{~K} \mathrm{~min}^{-1}$, these values have been paired with the solubility of hydrogen in pure iron as determined by A. Brass et al. from electochemical permeation 
Table 2 - Diffusion and trapping simulation parameters (1 TS) for pure iron $[27,28]$.

\begin{tabular}{lccccccc}
$\mu_{0}^{\mathrm{Fe}}\left(\mathrm{mol} \mathrm{H} \mathrm{mol} \mathrm{Fe}^{-1}\right)$ & $D_{0}^{\mathrm{Fe}}\left(\mathrm{cm}^{2} \mathrm{~s}^{-1}\right)$ & $E_{D}^{\mathrm{Fe}}\left(\mathrm{kJ} \mathrm{mol}^{-1}\right)$ & $k_{0}\left(\mathrm{~s}^{-1}\right)$ & $E_{k}\left(\mathrm{~kJ} \mathrm{~mol}^{-1}\right)$ & $p_{0}\left(\mathrm{~s}^{-1}\right)$ & $E_{p}\left(\mathrm{~kJ} \mathrm{~mol}^{-1}\right)$ & $n\left(\mathrm{~mol} \mathrm{trap} \mathrm{mol} \mathrm{Fe}^{-1}\right)$ \\
\hline $1.1 \cdot 10^{-6}$ & $7.2 \cdot 10^{-4}$ & 5.69 & $2.64 \cdot 10^{7}$ & 5.69 & $2.1 \cdot 10^{7}$ & 53.69 & $2.47 \cdot 10^{-5}$ \\
\hline
\end{tabular}

tests [28]. All simulations in this section will be carried out using these values, see Table $2[27,28]$.

Two different types of hydrogen charging will be looked at: (i) Type A referring to homogeneous charging of interstitial and trapped hydrogen in the material and (ii) Type B referring to a non-homogeneous charging, imposing a concentration gradient of both interstitial and trapped hydrogen in the material. These charging conditions are presented in Table 3 . The homogeneous charging of a $0.2 \mathrm{~cm}$ thick sample of pure iron can be achieved after 90 min of charging at both sample faces $(x=0$ and $x=L=0.2 \mathrm{~cm})$ at $298 \mathrm{~K}$ and will serve as the Type $\mathrm{A}$ conditions. Type $\mathrm{B}$ charging conditions will consist of $\mathrm{a}$ charging at one sample face $(x=0)$ for $3 \mathrm{~min}$ at $298 \mathrm{~K}$. The concentration profiles immediately after charging can be seen in Fig. 1. If these samples are subjected immediately to TDS analysis $\left(\phi=2 \mathrm{~K} \mathrm{~min}^{-1}\right)$, the resulting simulated TDS spectra can be seen in Fig. 2.

These spectra both present their strongest desorption flux at $t=0 \mathrm{~s}$ before quickly decreasing. One desorption peak can be observed for the homogeneously charged material (Type A), whereas a small desorption shoulder $(t=1000 \mathrm{~s})$ and one desorption peak can be seen for the material charged nonhomogeneously at one face (Type B). This intense desorption flux at $t=0 \mathrm{~s}$ may camouflage a significant part of low temperature spectral contributions, which may be attributed to trapping interactions, as the diffusion coefficient for $\mathrm{H}$ in pure iron at ambient temperature is very high therefore causing a strong and fast desorption from the sample at low temperatures.

Furthermore, it has been determined though simulations that the desorption spectra are representations of the combined simultaneous desorption of hydrogen from both sample faces, $x=0$ and $x=L$. This can be seen in Fig. 2 for Type $B$ charging (squares), where the total desorption flux, and the desorption flux from each face is shown. This demonstrates the need to know the actual hydrogen distribution and sample thickness in when simulating or analyzing TDS spectra. For a homogeneously charged material, this concurrent desorption occurs at the same intensity, as the concentration gradient in the sample is homogeneous (Type A), whereas for a "gradient" charged material (Type B), the desorption from the "noncharged" face, $x=L$, is seen much later, $t=2800 \mathrm{~s}$. This desorption from the non-charged face, reveals the diffusion

Table 3 - Charging conditions for simulating Type A (homogeneous) and Type B (partial) charging. $\mu_{0}^{\mathrm{Fe}}$ is taken to be the solubility of $\mathrm{H}$ in pure Fe [28].

\begin{tabular}{|c|c|c|c|c|}
\hline & \multicolumn{2}{|c|}{$\mu_{0}$} & \multirow[t]{2}{*}{$\mathrm{T}(\mathrm{K})$} & \multirow[t]{2}{*}{$t(\min )$} \\
\hline & $X=0$ & $x=L$ & & \\
\hline Type A & $\mu_{0}^{F e}$ & $\mu_{0}^{F e}$ & 298 & 90 \\
\hline Type B & $\mu_{0}^{F e}$ & 0 & 298 & 3 \\
\hline
\end{tabular}

and trapping interactions taking place internally in and across the material during TDS testing.

In experimental practices the sample is generally subjected to a transfer time between the hydrogen charging and the start of TDS testing (for example the time to pump to a sufficient vacuum for mass spectrometer usage) or maybe a room or high temperature aging period $[11,26,30]$. A transfer time of $30 \mathrm{~min}$ at $298 \mathrm{~K}$ has been selected in order to mimic this inevitable aging period. The concentration profiles for Type A and Type B charging, after this aging period, can be seen in Fig. 3. These profiles are significantly different from un-aged profiles, see Fig. 1, as the surface $\mathrm{H}$ concentration is significantly lower ( $\mu \approx \theta \cong 0$ ), the concentration of trapped hydrogen has also severely diminished and in pure iron the ratio of trapped to interstitial hydrogen has drastically increased. This leaves the concentration of interstitial $\mathrm{H}$ negligible in comparison to the concentration of trapped $\mathrm{H}$.

Furthermore for Type B (non-homogeneous) charging, the hydrogen distribution within the sample has shifted towards the interior, demonstrating the diffusion and trapping interactions taking place at room temperature. The resulting simulated spectra can be seen in Fig. 4 when TDS simulation is started from these aged concentration profiles.

These spectra strongly differ from the non-aged spectra (Fig. 2) as the desorption maximum is no longer at $t=0 \mathrm{~s}$ but later in analysis, corresponding to $\mathrm{T}_{m}=359 \mathrm{~K}$ for homogeneous charging. Furthermore, two well defined desorption peaks can be observed for Type B charging, $T_{m}=335 \mathrm{~K}$ and $\mathrm{T}_{m}=378 \mathrm{~K}$. In Fig. 4 the individual contributions of front side $(x=0)$ and back side $(x=L)$ desorption are represented along with the total (sum of the two contributions) desorption flux. This figure shows clearly that the desorption flux for a

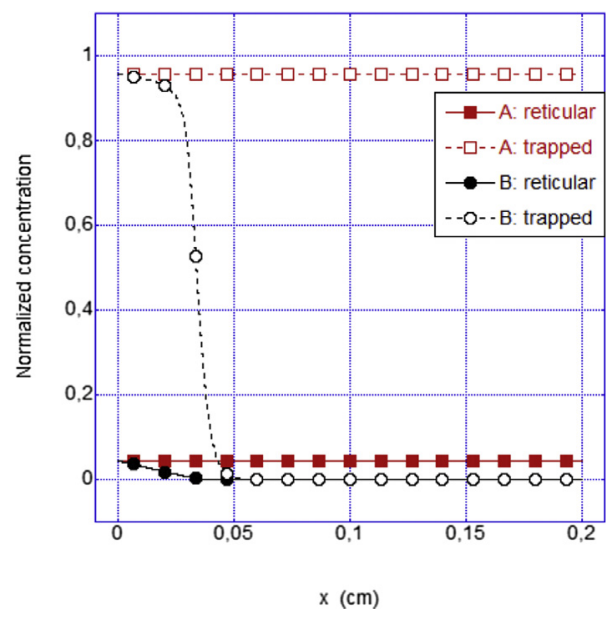

Fig. 1 - Simulated normalized interstitial and trapped hydrogen concentration profiles after charging. Profiles are normalized to the maximum total $\mathrm{H}$ concentration (interstitial + trapped) for each type. 


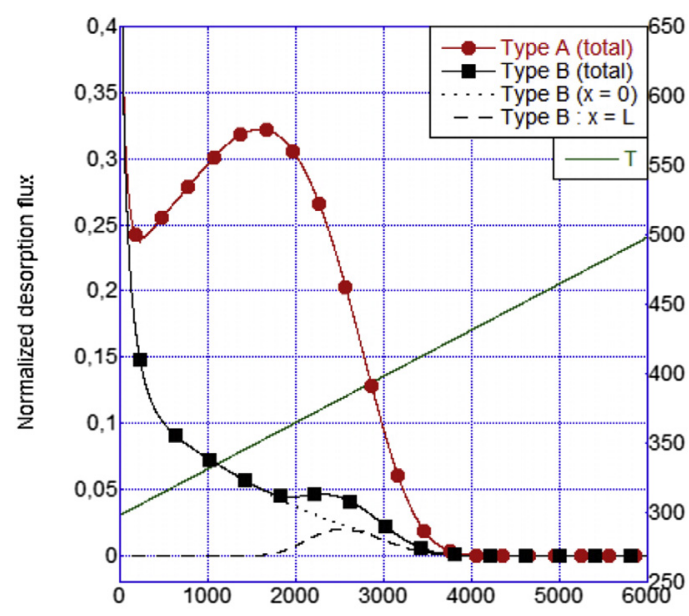

$t(s)$

Fig. 2 - Simulated normalized TDS spectrum immediately after hydrogen charging for Type $A$ and Type $B$ charging.

homogeneously charged material is made up of two simultaneous flux of equal intensity from both sample faces, due to the symmetry of the initial $c_{H}$ profile, whereas the second peak $\left(T_{m}=378 \mathrm{~K}\right)$ seen for a non-homogeneously charged material is due to the $\mathrm{H}$ desorption flux at $x=\mathrm{L}$.

This "double-peak" phenomenon is very troubling, as in many analytical spectral analysis methods each desorption peak is attributed to a separate trapping mechanism $[10,11,18,30,31]$. It should be restated that these simulations were done for a material presenting only homogeneously distributed TS, and therefore only one desorption peak was expected as suggested by some literature analysis methods. The fact that these simulations exhibit two peaks (due to the front and back desorption flux) shows the limits of such a classical spectral analysis technique, especially for a material presenting an internal concentration gradient.

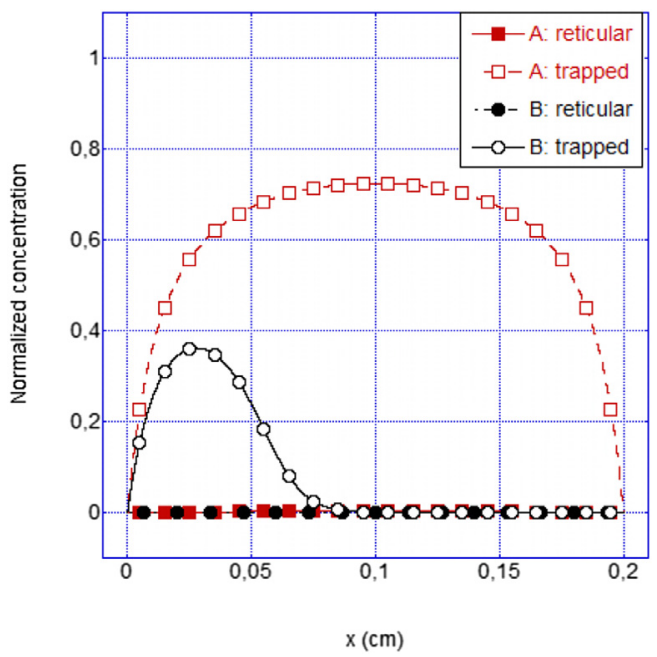

Fig. 3 - Simulated normalized concentration profiles for charging Type A and Type B after $30 \mathrm{~min}$ of aging at $298 \mathrm{~K}$.
In order to understand this observation, a Choo-Lee plot [10] was drawn for these two different charging conditions, Type A and Type B, from four simulated temperature ramps $\left(\phi=2,5,10,15 \mathrm{~K} \mathrm{~min}^{-1}\right)$. The simulated TDS spectra can be seen in Fig. 5 and the Choo-Lee plot can be seen in Fig. 6. Some general comments can be made on these simulated spectra: (i) the same general spectral shape is present for all temperature ramps respectively for each charging type (1 peak for Type $\mathrm{A}$ and 2 peaks for type B), (ii) with increasing $\phi$ the $T_{m}$ (s) is shifted towards higher temperatures, and (iii) the total $\mathrm{H}$ absorbed (integral of spectrum) is equivalent whatever the temperature ramp.

The assigned detrapping activation energy for Type A charging was determined to be $53.4 \mathrm{~kJ} \mathrm{~mol}^{-1}$, which is very close to the imposed $E_{p}$ value of $53.69 \mathrm{~kJ} \mathrm{~mol}^{-1}$. In this case Choo-Lee plot analysis seems to be a good approximation. When this analysis method was used to characterize both desorption peaks (Peak 1 and Peak 2 as assigned in Fig. 5b) observed with Type $\mathrm{B}$ charging the results are less accurate: the $E_{p}$ of $50.7 \mathrm{~kJ} \mathrm{~mol}^{-1}$ and $59.7 \mathrm{~kJ} \mathrm{~mol}^{-1}$ were determined respectively for Peak 1 and Peak 2 . These two derived $E_{p}$ values cannot be considered acceptable given the imposed simulation value, see Table 2. This observation, has highlighted another limit of the analytical techniques using the Kissinger equation [15], see Eq. (1). These results are consistent with the conclusions of Ebihara et al. [32,33], who state that the models based upon the Kissinger equations are limited to desorption spectra with only one peak.

As previously stated, one goal of this paper is to demonstrate the necessity for using a more complex numerical model to analyze TDS spectra. These simulations seem to disqualify the analytical Choo-Lee analysis technique [10] for non-homogeneous hydrogen charging. Moreover, these simulations were carried out on pure $\mathrm{Fe}$, a material presenting a relatively high interstitial $\mathrm{H}$ diffusion coefficient, therefore allowing a homogeneous hydrogen distribution to be achieved at room temperature in a relatively short period of time. Now if a homogeneous charging was desired for an austenitic stainless steel or a Ni-base alloy, this charging would take upwards of days [26] or weeks depending on both the sample thickness and charging temperature. Therefore for the majority of analysis done for fcc materials, the conditions do not satisfy the necessary requirements for Choo-Lee-Kissinger $[10,15]$ analysis. Furthermore, the impact of the unavoidable short aging period at ambient temperature before TDS analysis would be less significant on the $\mathrm{H}$ concentration profiles immediately before TDS, as in a fcc material $\mathrm{H}$ desorption and diffusion is much slower.

\section{Sample thickness}

Continuing the discussion concerning initial hydrogen distributions, sample thickness needs to be incorporated into analysis. Fig. 7 shows the effect of sample thickness $(0.02-10 \mathrm{~cm}$ ) for a charged (Type B) and aged (30 min at $298 \mathrm{~K}$ ) sample on the simulated TDS spectrum $\left(\phi=2 \mathrm{~K} \mathrm{~min}^{-1}\right)$ along with a small graphic insert of the trapped hydrogen concentration profiles before TDS analysis (y-axis: theoretical trapped $\mathrm{H}$ concentration, $\mathrm{x}$-axis: $\mathrm{x} / \mathrm{L}$ ). Any variation in sample thickness can have drastic effects on the resulting spectrum. 


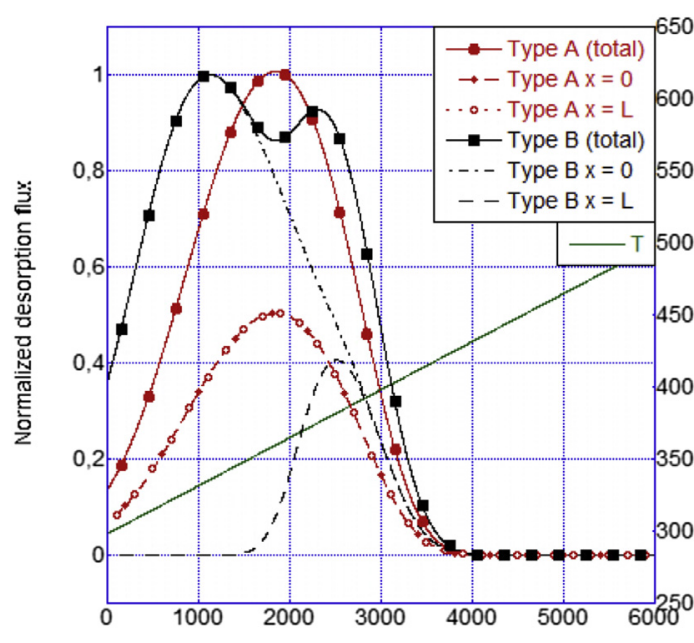

$\mathrm{t}(\mathrm{s})$

Fig. 4 - Simulated normalized TDS spectra for Type A and Type B charging subjected to $30 \mathrm{~min}$ of aging at $298 \mathrm{~K}$ between charging and TDS $\left(\phi=2 \mathrm{~K} \mathrm{~min}^{-1}\right)$. All desorption flux $(x=0$ and $x=L)$ are shown.

This parameter not only affects $T_{m}$ but also can affect the number of observed peaks which might render some analytical techniques quite difficult or false, for example the classical Choo-Lee plot method [10]. It seems that to be able to work with a single peak TDS spectrum, either a very thin or very thick sample is needed. These types of simulations, before TDS testing, appear useful when choosing the specimen geometry depending on the desired final spectrum. It would seem that in a material presenting a high diffusivity of $\mathrm{H}$, pure iron for example, very small variations would have little effect, but for a material presenting a much lower $\mathrm{H}$ diffusivity, FCC materials such as stainless steel 316L or nickel alloy 600 , very small variations would have drastic effects on the resulting spectrum. The effect of sample thickness has been discussed by several other authors, specifically Ebihara et al. $[32,33]$ and will not be further discussed in this article.

\section{Experimental temperature ramp}

Furthermore in experimental analysis, certain experimental configurations and laboratory set-ups may not allow for a perfectly linear and reproducible TDS temperature ramp with every test. Slight differences in temperature ramp can have an important impact on the resulting TDS spectrum as $D, k$, and $p$ are considered to present Arrhenius relationships and are therefore temperature dependent. Fig. 8 shows the extreme sensitivity of a TDS spectrum to temperature when comparing a simulated spectrum using a linear $2 \mathrm{~K} \mathrm{~min}^{-1}$ ramp rate to an experimental acquired temperature ramp of the same rate. The experimental temperature shown in Fig. 8, was measured in-situ in the TDS system at the Laboratoire d'Etude de la Corrosion Aqueuse at the CEA Saclay using a type-K thermocouple placed next to the sample, the furnace is controlled using an external system. Both the spectral form and $T_{m}$ of

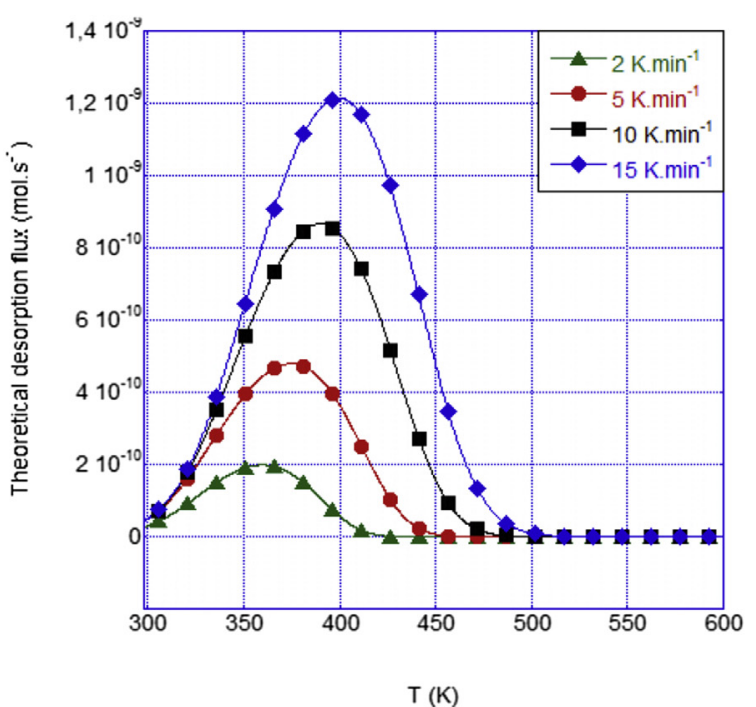

(a)

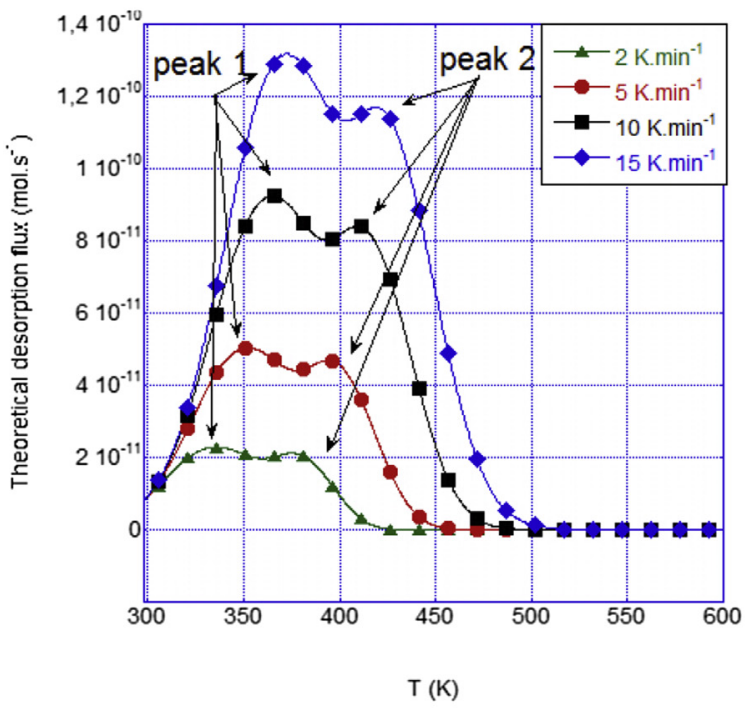

(b)

Fig. 5 - Simulated theoretical desorption spectra for $\phi$ ranging from 2 to $15 \mathrm{~K} \mathrm{~min}^{-1}$ for charging (a) Type $A$ and (b) Type B. Simulations incorporated a $30 \mathrm{~min}$ aging period between charging and TDS analysis.

desorption are drastically affected. In order to avoid this problem and analysis issues two solutions may be proposed: (i) taking into consideration the experimental temperature ramp (T[t]) in simulations [34] or (ii) the experimental temperature ramp would need to be extremely well controlled in order to assure a perfectly linear and reproducible experimental $\mathrm{T}$ ramp.

\section{Trapping parameters}

Most analysis methods are aimed at determining the detrapping energy associated with a specific TS, typically those using 


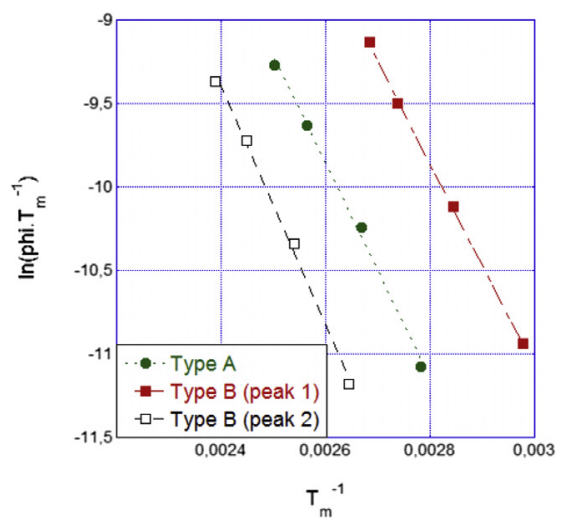

\begin{tabular}{c|ccc} 
& \multicolumn{3}{|c}{$T_{m}(\mathrm{~K})$} \\
$\phi\left(\mathrm{K}^{\prime} \mathrm{min}^{-1}\right)$ & Type A & Type B \\
\hline 2 & & Peak 1 & Peak 2 \\
5 & 359 & 335 & 378 \\
10 & 374 & 351 & 392 \\
15 & 389 & 365 & 408 \\
\hline$E_{p}\left(\mathrm{~kJ} . \mathrm{mol}^{-1}\right)$ & 399 & 372 & 418 \\
\hline
\end{tabular}

Fig. 6 - Choo-Lee plots for all observed peaks in simulated TDS spectra for Fe pure charged Type A and Type B seen in Fig. 5 and the corresponding $T_{m}$ and derived $E_{p}$ values.

the Kissinger equation fast resolution techniques whose limits have been mentioned earlier in this paper [10], and usually neglect other important kinetic parameters such as: $k_{0}, p_{0}, E_{k}$, respectively the trapping pre-exponential constant, the detrapping pre-exponential constant, and the trapping activation energy. However, several more recent papers have highlighted that $k_{0}$ and $p_{0}$ may be also of great importance and will therefore not be neglected in simulations [33]. In this

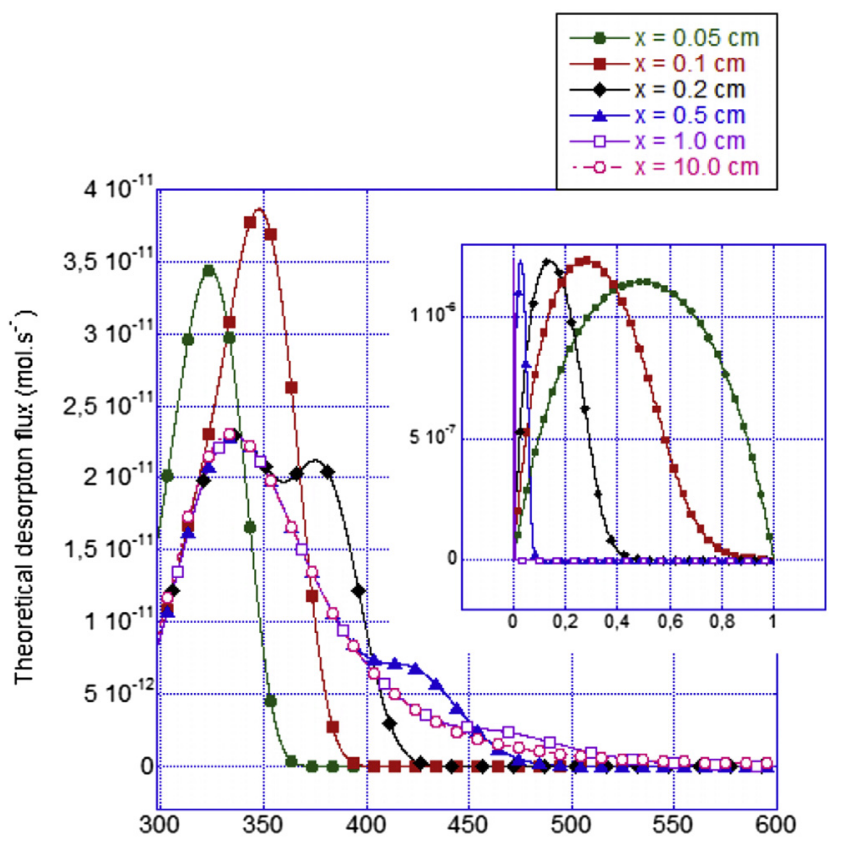

$\mathrm{T}(\mathrm{K})$

Fig. 7 - Effect of sample thickness on final desorption spectra $\left(\phi=2 \mathrm{~K} \mathrm{~min}^{-1}\right)$ for a charging of Type B aged $30 \mathrm{~min}$ at room temperature between charging and TDS. The graphic insert presents the concentration profiles (after aging) before TDS with normalized L (y-axis: concentration (mol) and $x$-axis: normalized sample thickness $(x / L))$. section, the influence of these parameters on TDS spectra will be discussed.

\section{Pre-exponential constants}

The effect of "jump probabilities" has been mentioned in several articles $[33,35]$ but is neglected in analytical spectral investigation methods. When determining these parameters, analysis becomes more difficult and a more complex numerical routine is required. The pre-exponential constants, $k_{0}$ and $p_{0}$, determine the probability of hydrogen jumping from trap sites to interstitial sites and vice-versa. The following sections will demonstrate the effect of "jump-probability" variations on the resulting simulated TDS spectra. In the first subsection the pre-exponential constants were varied one at a time over several orders of magnitude while holding all other parameters constant (see Table 2). In the second subsection, the ratio of $k_{0} / p_{0}$ is held at 1.25 and the individual values are adjusted accordingly while all other parameters are kept constant (see Tables 2 and 4).

Individual variation

Slight adjustments of the pre-exponential constants can influence the filling and emptying of trap sites. When the trapping probability $\left(k_{0}\right)$ is increased, the desorption maximum is shifted towards higher temperatures, see Fig. 9a, whereas the inverse is observed with an increase in detrapping probability $\left(p_{0}\right)$, see Fig. $9 \mathrm{~b}$. This is logical as when trapping probability is increased the likelihood for hydrogen to be trapped/retrapped is very high, and therefore hydrogen is readily trapped and/or retrapped during charging, transfer, and TDS analysis. On the other hand increasing the detrapping probability would increase the chance that the hydrogen will be released from the trap site and therefore hydrogen will be quickly detrapped from the TS. It can be concluded that individually these parameters have an important impact on the resulting TDS spectrum and should be included in analysis.

Constant $\mathrm{k}_{0} / \mathrm{p}_{0}$ ratio

In studies where the pre-exponential constants are investigated, they are often analyzed by holding their ratio constant 


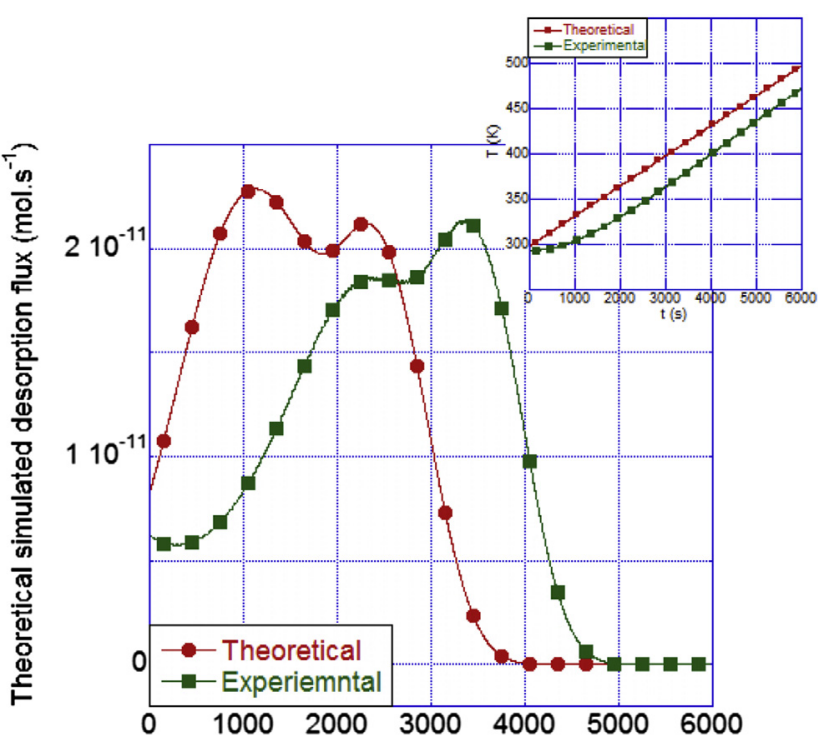

$t(\mathbf{s})$

Fig. 8 - Simulated TDS spectrum for a linear theoretical T ramp $\left(\phi=2 \mathrm{~K} \mathrm{~min}^{-1}\right)$ as compared to an experimental $\mathrm{T}$ $\operatorname{ramp}\left(\phi=2 \mathrm{~K} \mathrm{~min}^{-1}\right)$. The graphic insert shows the linear $\mathrm{T}$ ramp as compared to an experimental acquired $\mathrm{T}$ ramp: $y$-axis: $T(K), x$-axis: $t(s)$.

[27]. This approach will be explored in this section. These simulations were conducted by holding the $k_{0} / p_{0}$ ratio constant $\left(k_{0} / p_{0}=1.25\right)$, see Table 4 and Fig. 10. It is clear that even when the ratio is held constant, the individual values have an effect on the resulting TDS spectrum. For example as the jump probabilities are increased from A to $F$ (Table 4), values on the order of $10^{4} \mathrm{~s}^{-1}$ to $10^{10} \mathrm{~s}^{-1}$, the $\mathrm{T}_{m}$ shifts to lower temperatures $\left(T_{m}^{A}>T_{m}^{B}>T_{m}^{C}\right)$ and eventually at higher $k_{0}$ and $p_{0}$ values $\left(\geq 10^{6} \mathrm{~s}^{-1}\right)$ a second desorption peak appears (D-F) and at very high values of $k_{0}$ and $p_{0}\left(D-F, \geq 10^{7} \mathrm{~s}^{-1}\right)$ the spectra are nearly identical Fig. 10. It should be noted that the spectra (D, $\mathrm{E}$, and F) are not identical but the differences in the simulated desorption values are too small to be seen in the presented figure. The forward (trapping) and backward (detrapping) reaction rates are too fast to have any further impact on the system. This might show that the DTS is approaching a pseudo-equilibrium state as the "jump-probabilities" approach infinity, but the likelihood that kinetic constants

Table 4 - Simulation constants used when holding the $k_{0} / p_{0}$ ration constant at 1.25 . The resulting spectra can be seen in Fig. 10 and are labeled using an alphabetic key.

\begin{tabular}{lll} 
Label (Fig. 10) & $k_{0}\left(\mathrm{~s}^{-1}\right)$ & $p_{0}\left(\mathrm{~s}^{-1}\right)$ \\
\hline $\mathrm{A}$ & $2.6410^{4}$ & $2.110^{4}$ \\
$\mathrm{~B}$ & $2.6410^{5}$ & $2.110^{5}$ \\
$\mathrm{C}$ & $2.6410^{6}$ & $2.110^{6}$ \\
$\mathrm{D}$ & $2.6410^{7}$ & $2.110^{7}$ \\
$\mathrm{E}$ & $2.6410^{8}$ & $2.110^{8}$ \\
$\mathrm{~F}$ & $2.6410^{10}$ & $2.110^{10}$ \\
\hline
\end{tabular}

greater than $10^{7} \mathrm{~s}^{-1}$ will need to be addressed. Furthermore, if diffusion and trapping interactions were simulated in a material with much slower diffusion, for example a fcc metal, Nibase alloys, or stainless steels, one can image the effect of the pre-exponential constants would be heightened.

This section has demonstrated the influence of the preexponential constants on simulated TDS spectra. It is clear that these individual parameters have a direct impact on the resulting spectra and therefore must be considered in analysis. This section has shown that when the pre-exponential constant ratios are held constant and the individual parameters $\left(k_{0}\right.$ and $\left.p_{0}\right)$ are increased accordingly, it leads to an equivalent result as the one obtained by considering a local equilibrium hypothesis.

\section{Activation energies}

Most analytical methods to date focus on determining only the detrapping activation energy $\left(E_{p}\right)$ [10], and consider this information sufficient for TS characterization. The effect of both trapping and detrapping activation energies will be explored in the following sections. First, simulations were conducted fixing all parameters (diffusion and trapping/ detrapping pre-exponential constants) while the respective trapping and detrapping activation energies were varied individually (this changes the respective binding energy $\left(E_{b}\right)$ associated with the $E_{k}$ and $E_{p}$ combination), see values in Table 2. Then simulations were carried out when $E_{b}$ has been held constant, along with all other parameters, and $E_{k}$ and $E_{p}$ varied accordingly, see Tables 2 and 5.

\section{Individual variation}

When the activation energies are evaluated separately, some observations can be made concerning the trapping activation energy (Fig. 11a) and detrapping activation energy (Fig. 11b). When $E_{k}$ is low $\left(E_{k}<E_{D}\right.$, green circles Fig. 11a), $\mathrm{H}$ trapping is very easy, therefore allowing traps to become more saturated during charging and low temperature aging (i.e. $30 \mathrm{~min}$ at $298 \mathrm{~K})$. Therefore the desorption flux is significantly more intense than when $E_{k} \geq E_{D}$. When $E_{k}$ is greater $\left(E_{k}>E_{D}\right.$, black diamonds and blue triangles Fig. 11a), the total concentration of trapped $\mathrm{H}$ becomes low, as during aging $\mathrm{H}$ diffuses very readily out of the sample and cannot be easily retrapped.

Concerning detrapping activation energy, when $E_{p} \leq E_{D}$ (green circles and red squares Fig. 11b) detrapping is as easy as or easier than diffusion. Therefore after the aging period ( $30 \mathrm{~min}$ at $298 \mathrm{~K}$ ) very little trapped or interstitial hydrogen left in the sample. When $E_{p}$ is increased (black diamonds and blue triangles, Fig. 11b), detrapping becomes increasingly more difficult and $\mathrm{H}$ is accumulated in TS during both charging and aging. Moreover this "trapped" hydrogen is released at higher T during TDS, which can be attributed to the stronger $E_{p}$ and "binding energy".

\section{Constant binding energy $\left(\mathrm{E}_{\mathrm{b}}\right)$}

The TS binding energy can be considered as the difference between the detrapping and trapping activation energy $\left(E_{b}=E_{p}-E_{k}\right)$ and is often used by researchers in trapping analysis methods. Often simulations are carried out imposing a constant binding energy $\left(E_{b}\right)$. In this section the binding 


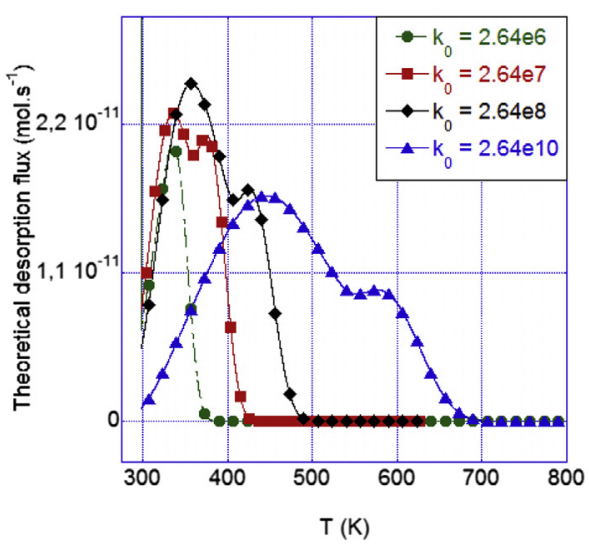

(a)

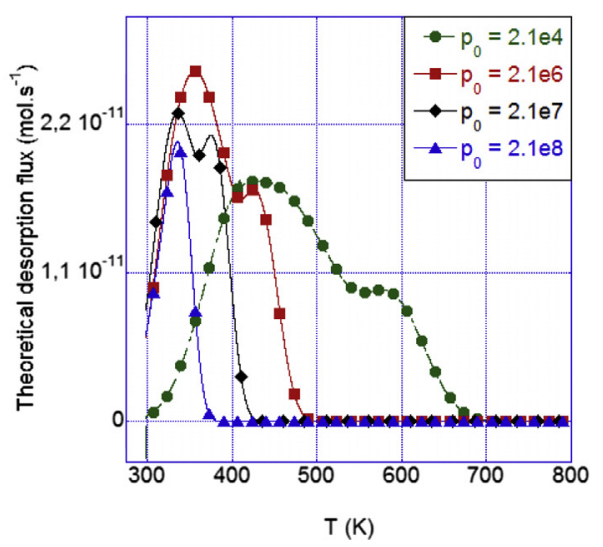

(b)

Fig. 9 - Effect of pre-exponential factor: (a) $k_{0}$ and (b) $p_{0}$, on simulated TDS spectra $\left(\phi=2 \mathrm{~K} \min ^{-1}\right)$ for aged (30 min at $\left.298 \mathrm{~K}\right)$ samples of charging Type $B$.

energy $\left(E_{p}-E_{k}\right)$ was fixed at $48.00 \mathrm{~kJ} \mathrm{~mol}^{-1}$ and the $E_{k}$ and $E_{p}$ values were varied accordingly. The simulation values can be seen in Table 5 . The resulting simulations can be seen in Fig. 12.

Even when $E_{b}$ is kept constant, the $E_{k}$ and $E_{p}$ combination has an effect on the TDS spectrum. Increasing the respective $E_{k}$ and $E_{p}$ values from $A$ to $F$ results in an increase in the intensity of the first desorption peak (desorption flux from $x=0$ ), an increase in the total $\mathrm{H}$-desorption flux (which hits at the difference in $\mathrm{H}$ absorbed during charging and retention of hydrogen in the TS during the aging period (30 min at $298 \mathrm{~K})$ ), and very little change in the intensity/placement of the second desorption peak (desorption flux from $x=L$ ). The increase in the first desorption peak's intensity can be attributed to the increasing difficulty for the hydrogen to become detrapped,

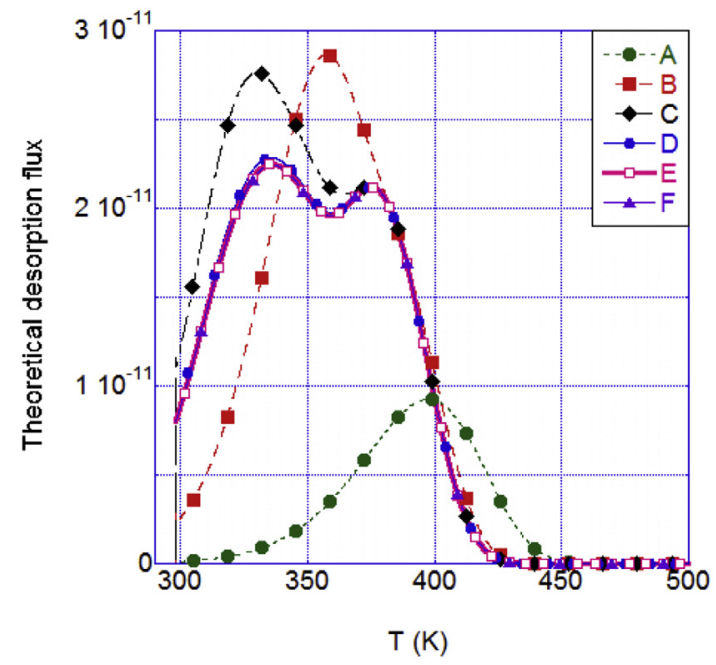

Fig. 10 - Influence of $k_{0} / p_{0}$ with a constant ratio $\left(k_{0} /\right.$ $\left.p_{0}=1.25\right)$ on a simulated TDS spectrum $\left(\phi=2 \mathrm{~K} \mathrm{~min}^{-1}\right)$, see Table 4 for the corresponding $k_{0}$ and $p_{0}$ simulation values (A-F). The samples were Type B charged (Table 3) and aged $30 \mathrm{~min}$ at $298 \mathrm{~K}$. and therefore a greater amount stays trapped in the TS close to the charged surface $(x=0)$ and less is detrapped and subsequently desorbed during the aging period. Furthermore the variation in $T_{m}$ of the first desorption peak, for simulated TDS spectra A, B, C, D, and E, while being very small, is globally in good agreement with the common consensus in literature (i.e. as $E_{p}$ is increased $T_{m}$ will shift to higher temperatures [10]).

Furthermore, when $E_{k}$ and $E_{p}$ are increased (while keeping $E_{b}$ constant) to much higher energies than that of interstitial diffusion ( $E_{D}$, Table 2), for example spectrum $F$ in Fig. 12, a significant decrease in the total desorption flux is observed along with a change in spectral form. Instead of having two well defined desorption peaks, the spectrum is characterized by one desorption peak (desorption flux from $x=0$ ) and one small desorption shoulder (desorption flux from $x=L$ ). This can be explained by the difficulty hydrogen has to become trapped, $E_{k}>E_{D}$, (attributing to the overall significantly lower total desorption flux) and a great deal of $\mathrm{H}$ preferentially diffusing by the interstitial sites. Furthermore $T_{m}$ of the single peak is shifted to a much higher temperature hinting at a much higher $E_{p}$ and demonstrating the difficulty of $\mathrm{H}$ to become detrapped.

In the previous sections, the simulations have shown that both the activation energy associated with trapping $\left(E_{k}\right)$ and detrapping $\left(E_{p}\right)$ along with their respective pre-exponential constants $\left(k_{0}, p_{0}\right)$ are important. It is necessary to determine all these parameters in order to have accurate information concerning interstitial diffusion and trapping interactions. It can also be observed that as the activation energies $\left(E_{k}\right.$ and $\left.E_{p}\right)$ are decreased from $\mathrm{F}$ to $\mathrm{A}$ (Fig. 12 and Table 5) and as preexponential constants $\left(k_{0}\right.$ and $\left.p_{0}\right)$ are increase while keeping their ratio constant from A to F (Fig. 10 and Table 4) the spectral variations become less evident hinting that the system might be approaching a pseudo-equilibrium state, and cases where a $D_{\text {eff }}$ and the local thermodynamic equilibrium hypothesis might be applicable. Furthermore, as the influence of these four parameters on the overall system has been demonstrated and discussed in-depth, it can be concluded that in order to be able to sufficiently analyze $\mathrm{H}$ diffusion and 
Table 5 - Trapping $\left(E_{k}\right)$ and detrapping $\left(E_{p}\right)$ activation energies used when holding the binding energy constant $\left(E_{b}\right)$ at $48.00 \mathrm{~kJ} \mathrm{~mol}^{-1}$

\begin{tabular}{lcc} 
Label (Fig. 12) & $E_{k}\left(\mathrm{~kJ} \mathrm{~mol}^{-1}\right)$ & $E_{p}\left(\mathrm{~kJ} \mathrm{~mol}^{-1}\right)$ \\
\hline A & 1.00 & 49.00 \\
B & 2.00 & 50.00 \\
C & 5.69 & 53.69 \\
D & 10.00 & 58.00 \\
E & 15.00 & 63.00 \\
F & 20.00 & 68.00 \\
\hline
\end{tabular}

trapping systems a more robust numerical method, which determines all these parameters (not only $E_{b}$ or $E_{p}$ and the $k_{0} /$ $p_{0}$ ratio), must be used.

\section{Proposed numerical model and analysis technique}

The previous sections have revealed the necessity of considering all kinetic trapping-detrapping parameters in diffusiontrapping systems, previously referred to as DTS, along with the importance of injecting the experimental parameters that have an impact on the trapped and interstitial $\mathrm{H}$ concentration profiles, this includes the experimental temperature ramp, charging duration and temperature, and transfer duration and temperature, as well as the sample thickness. By injecting these parameters the diffusion, trapping, and detrapping phenomena taking place during these stages are taken into consideration, as the importance of sample "history" has been demonstrated and discussed earlier. It appears that it will be necessary to use a numerical model which has the capability to determine simultaneously all four kinetic parameters relative to trapping and detrapping. This would require simulation using the original McNabb and Foster equations, Eqs. (2)-(3), and a numerical routine in order to determine the diffusion and trapping constants.

Such a model would also need to deal with interstitial diffusion and determine the associated constants $\left(D_{0}, E_{D}\right)$.
Such a numerical code has been developed. In order to determine the diffusion coefficient and kinetic trapping constants, a multi-step iterative method coupling numerical simulation with experimental spectrum will be proposed.

This method involves working with "model materials", referred to here as MM. The term MM refers to the use of a material presenting only $\mathrm{H}$-diffusion interactions, a pure diffusion system, referred to as a PDS, or a material having one or several types of TS. A system having one type of TS would present a specific combination of $\mathrm{H}$-diffusion-trapping/ detrapping interactions or DTS. These DTS could include the well known TS types such as dislocations, vacancies, and/or precipitates $[2-4,10,36,37]$ as well as other suspected TS types. These "model materials" would serve to isolate specific diffusion and/or trapping interactions and help with spectral deconvolution.

These proposed MM can be fabricated through a series of thermal and/or mechanical treatments in order to create the desired TS type and microstructure in a controlled manner. For example, a high temperature thermal treatment and rapid quench followed by tempering may be used to bring an industrial material from its initial as-received material state to a PDS state. The high temperature thermal treatment and quench would eliminate all residual cold-working and dislocations as well as solubilize the precipitates present in the material and the tempering serve to annihilate the vacancies created during the quench. Furthermore, this PDS material could be then subjected to a mechanical treatment to create dislocations or other thermal treatments recreating, for example, precipitates or vacancies and thereby creating a DTS.

These MM would be used to acquire a set of experimental "model" TDS spectra for each type of isolated H-material interactions. For example, the PDS material would be used to acquire a series of reference TDS spectra where the only spectral contribution is due to interstitial diffusion. These spectra would then be fit using the developed numerical routine deriving the specific diffusion parameters, $D_{0}$ and $E_{D}$, associated with interstitial diffusion in the material. This code also takes into consideration the experimental temperature

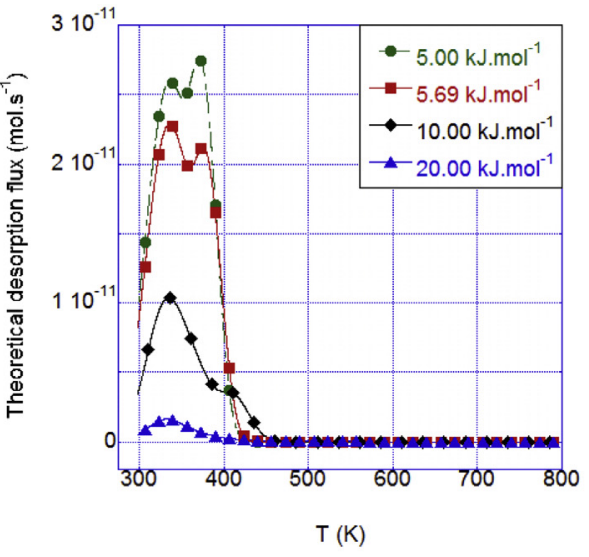

(a)

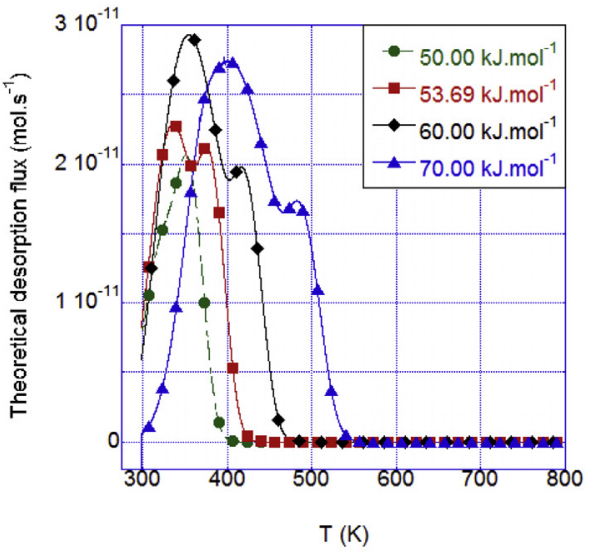

(b)

Fig. 11 - Effect of activation energy: (a) $E_{k}$ and (b) $E_{p}$, on simulated TDS spectra $\left(\phi=2 \mathrm{~K} \mathrm{~min}^{-1}\right.$ ) for aged samples of charging Type $B$. 


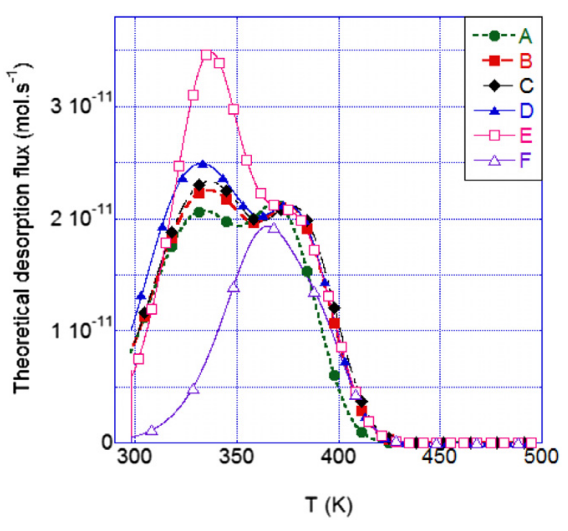

Fig. 12 - Influence of $E_{k}$ and $E_{p}$ when $E_{b}$ is held constant at $48 \mathrm{~kJ} \mathrm{~mol}^{-1}$ on simulated TDS spectra, see Table 5 for the corresponding $E_{k}$ and $E_{p}$ simulation values $(A-F)$. The samples were supposed charged using Type B conditions (Table 3) and aged $30 \mathrm{~min}$ at $298 \mathrm{~K}$.

ramp, sample measurements and experimental conditions, i.e. the charging and transfer time and temperature. This is described in diagram seen in Fig. 13.

These derived diffusion parameters would then be reinjected into the simulation code, along with the experimental desorption flux, temperature ramp, and experimental conditions for the DTS "model" TDS spectrum. The code then determines the pre-exponential constants $\left(k_{0}, p_{0}\right)$ and activation energies $\left(E_{k}, E_{p}\right)$ associated with the specific trappingdetrapping system.

This iterative method, coupling experimental data with numerical simulation, would derive all six constants $\left(D_{0}, k_{0}\right.$, $\left.p_{0}, E_{D}, E_{k}, E_{p}\right)$ associated with the diffusion coefficient and kinetic trapping interactions using a two step process. This approach would allow for the diffusion coefficient constants to be derived separately before the four kinetic trapping and detrapping parameters. Furthermore, for each DTS, for example for diffusion-dislocations, diffusion-vacancies, or diffusion-precipitates systems, the derived kinetic reaction constants would serve to construct a database of kinetic information for individual TS types. This database of kinetic constants could later be used to simulate more complicated materials presenting more that one trap site type.

In order to demonstrate the necessity of working with $\mathrm{MM}$, one can envisage this same type of approach (spectral acquisition followed by numerical fitting) done with an industrial material. It can be imagined that interstitial diffusion along with an unknown amount of TS types, and therefore unknown number of kinetic trapping-detrapping interactions, are present in an untreated industrial material. Spectral interpretation and the subsequent deriving of the diffusion coefficient and trapping/detrapping kinetic constants from a TDS spectrum for a material presenting only one TS would require the simultaneous fitting of six parameters and for a material presenting two trap sites ten parameters. The accurate derivation of ten parameters simultaneously may prove very difficult and produce inconclusive results.

For a MM a maximum of four kinetic parameters would need to be determined from a single fit. Furthermore, a kinetic parameter validation test would be put in place. This validation process would include determining a specialized thermal cycle, aimed at exalting specific kinetic parameters, from simulations using the derived set of diffusion and kinetic parameters for either a PDS or DTS. The resulting experimental TDS spectrum, having experienced the same thermal cycle, would be compared to the simulation results, thereby

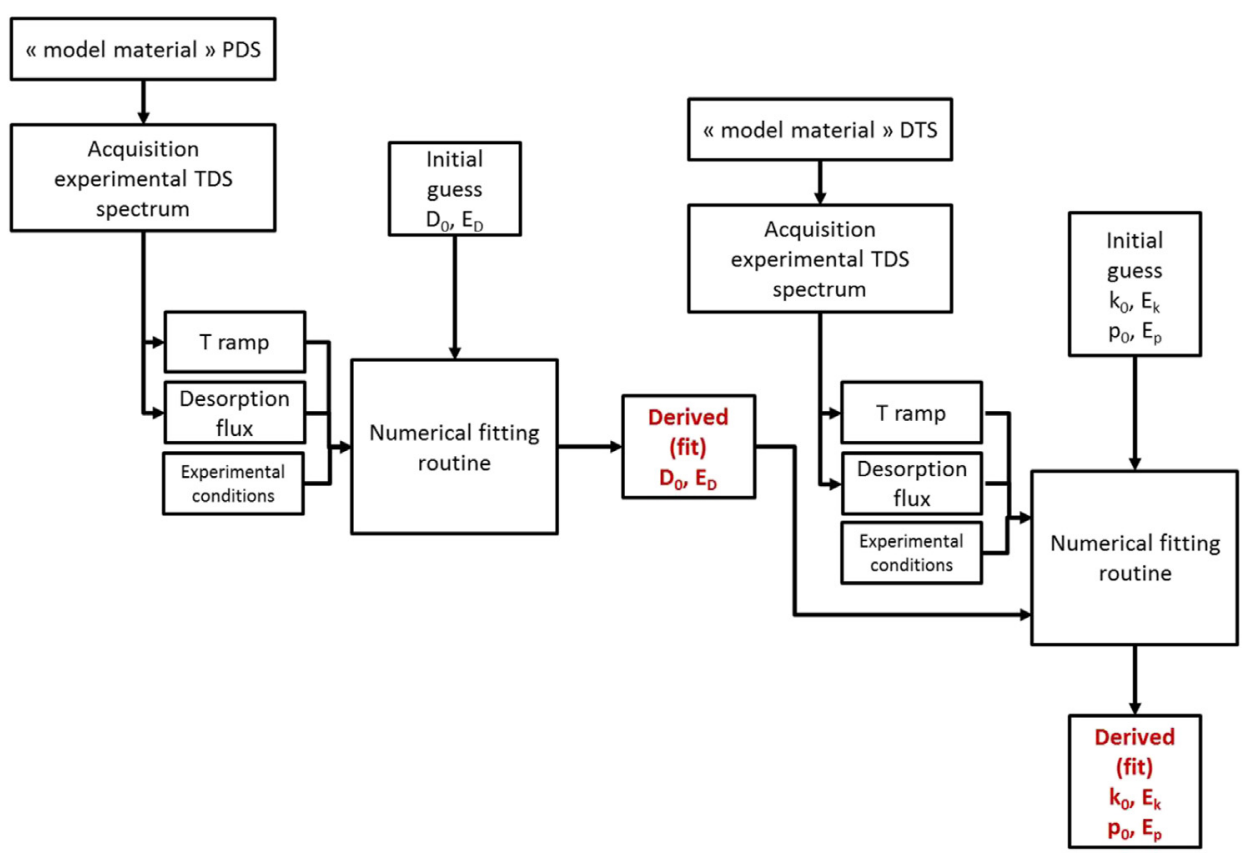

Fig. 13 - Logic diagram of proposed analysis method coupling experimental results with a numerical analysis fitting technique in order to derive both the diffusion and trapping/detrapping parameters. 
determining the robustness and overall accuracy of the derived kinetic trapping and detrapping constants.

\section{Conclusions}

Thermal desorption mass spectroscopy proves to be a very powerful and useful experimental tool with the potential to provide access to kinetic information concerning hydrogenmaterial interactions, specifically with respect to diffusion and trapping. Simulations have revealed that today's most commonly used analytical spectral analysis techniques may give information concerning the detrapping activation energy, but only when certain conditions are met, for example a nearly homogeneous hydrogen concentration before spectral acquisition. This hydrogen homogeneity can be relatively easily met when working with a thin material presenting a high hydrogen solubility and diffusivity (ie. pure iron and lowcarbon/alloyed steels), but these conditions become very difficult to achieve when these coefficients are not as high (ie. austenitic stainless steels, Ni-base alloys).

The simulations presented here have been directed at highlighting the importance of taking into consideration the experimental sample history, including the charging conditions, transfer time, and the experimental TDS temperature ramp, along with sample parameters such as thickness. These simulations have helped to shed some light on possible problems encountered during the analysis of experimental TDS spectra. It is necessary to work with an analysis method that has been well adapted to these conditions and is robust enough to handle variations in these parameters.

The proposed numerical model and analysis technique is easily adaptable to different types of materials and TS types present in the material through working with "model materials" in order to construct a database of diffusion and kinetic trapping/detrapping information. Once constructed this database of kinetic constants could be used to simulate and predict $\mathrm{H}$-material interactions for a material presenting numerous types of TS. This proposed numerical model coupled with $\mathrm{MM}$ in order to acquire trapping/detrapping kinetic information is currently being realized for several industrial materials.

\section{Acknowledgments}

The authors would like to sincerely thank EDF for their financial support.

\section{R E F E R E N C E S}

[1] Darken L, Smith RP. Behavior of hydrogen in steel during and after immersion in acid. Corr Nace 1948:1-16.

[2] Lecoester F, Chêne J, Noel D. Hydrogen embrittlement of the Ni-base alloy 600 correlated with hydrogen transport by dislocations. Mater Sci Eng A 1999;262:173-83.

[3] Pressouyre G. A classification of hydrogen traps in steel. Metall Trans A 1979;10:1571-3.
[4] Pressouyre G. Hydrogen traps, repellers, and obstacles in steel; consequences on hydrogen diffusion, solubility, and embrittlement. Metall Trans A 1983;14A:2189-93.

[5] Brass A, Chêne J. Influence of deformation on the hydrogen behavior in iron and nickel base alloys: a review of experimental data. Mater Sci Eng A 1998:210-21.

[6] Dadfarnia M, Sofronis P, Neeraj T. Hydrogen interaction with multiple traps: can it be used to mitigate embrittlement? Int J Hydrogen Energy 2011;36(16):10141-8.

[7] Dieudonné T, Marchetti L, Wery M, Miserque F, Tabarant M, Chêne J, et al. Role of copper and aluminum on the corrosion behavior of austenitic Fe-Mn-C TWIP steels in aqueous solutions and the related hydrogen absorption. Corr Sci 2014;83:234-44.

[8] Lynch S. Mechanisms of hydrogen assisted cracking - a review. In: Moody N, Thompson A, Ricker R, Was G, Jones R, editors. Hydrogen effects on materials behavior and corrosion deformation interactions, vol. 1. Warrendale, PA: TMS; 2003. p. 449-66. 15089-7528.

[9] Jambon F, Marchetti L, Jomard F, Chêne J. Mechanism of hydrogen absorption during the exposure of alloy 600-like single-crystals to PWR primary simulated media. J Nucl Mater 2011;414(3):386-92.

[10] Choo W, Lee J. Thermal analysis of trapped hydrogen in pure iron. Metall Mater Trans A 1982;13A:135-40.

[11] Choo W, Lee JY. Hydrogen trapping phenomena in carbon steel. J Mater Sci 1982;17:1930-8.

[12] Kasuya T, Fuji M. Diffusion with multiple kinds of trapping sites. J Appl Phys 1998;83:3039-48.

[13] McNabb A, Foster P. A new analysis of the diffusion of hydrogen in iron and ferritic steels. Trans Metall Soc AIME 1963;227:618-27.

[14] Oriani R. The diffusion and trapping of hydrogen in steel. Acta Mater 1970;18:147-57.

[15] Kissinger H. Reaction kinetics in differential thermal analysis. Anal Chem 1957;29(11):1702-6.

[16] Sarrazin P, Galerie A, J. F. Mechanisms of high temperature corrosion: a kinetic appoach. Zurich, Switzerland: Trans Tech Publications, Ltd; 2008.

[17] Soustelle M. Heterogenous kinetics handbook. Hoboken, USA: John Wiley \& Sons; 2010.

[18] Frappart S, Oudriss A, Feaugas X, Creus J, Bouhattate J, Thébault F, et al. Hydrogen trapping in martensitic steel investigated using electrochemical permeation and thermal desorption spectroscopy. Scr Mater 2011;65(10):859-62.

[19] Kirchheim R. Keynote lecture: diffusion controlled thermal desorption spectroscopy. In: OCAS, editor. Steelyhydrogen 2nd international conference on steel and hydrogen, vol. 1. OCAS; 2014. p. 237-53.

[20] Svoboda J, Fischer FD. Modelling for hydrogen diffusion in metals with traps revisited. Acta Mater 2012;60(3):1211-20.

[21] Svoboda J, Mori G, Prethaler A, Fischer FD. Determination of trapping parameters and the chemical diffusion coefficient from hydrogen permeation experiments. Corr Sci 2014;82:93-100.

[22] Fischer FD, Svoboda J, Kozeschnik E. Interstitial diffusion in systems with multiple sorts of traps. Modell Simul Mater Sci Eng 2013;21(2):025008.

[23] Fischer FD, Mori G, Svoboda J. Modelling the influence of trapping on hydrogen permeation in metals. Corr Sci 2013;76:382-9.

[24] Mavrikakis M, Schwank JW, Gland JL. The effects of exposure time and pressure on the temperature-programmed desorption spectra of systems with bulk states. Surf Sci 1996;355:L385-92.

[25] Mavrikakis M, Schwank JW, Gland JL. Temperature programmed desorption spectra of systems with 
concentration gradients in the solid lattice. J Phys Chem 1996;100(7):11389-95.

[26] Yagodzinskyy Y, Todoshchenco O, Papula S, Hãnninen H. Hydrogen solubility and diffusion in austenitic stainless steels studied with thermal desorption spectroscopy. Steel Res J 2011;82(1):20-5.

[27] Turnbull A, Hutchings R, Ferriss D. Modelling of thermal desorption of hydrogen from metals. Mater Sci Eng A 1997;238:317-28.

[28] Brass A, Guillon F, Vivet S. Quantification of hydrogen diffusion and trapping in $2.25 \mathrm{Cr}-1 \mathrm{Mo}-\mathrm{V}$ steels with the electrochemical permeation technique and melt extractions. Metall Mater Trans A 2004;35A:1449-64.

[29] Baskes M. A calculation of the surface recombination rate constant for hydrogen isotopes on metals. J Nucl Mater 1980;92:318-24.

[30] Wei F-G, Hara T, Tsuzaki K. Precise determination of the activation energy for desorption of hydrogen in two Ti-added steels by a single thermal-desorption spectrum. Metall Mater Trans B 2004;35 B:587-97.

[31] Lee J, Lee J, Choo W. Thermal analysis of trapped hydrogen in AISI 4340 steel. Metal Sci 1982:423-7.

[32] Ebihara K, Kaburaki H, Suzudo T, Takai K. A numerical study on the validity of the local equilibrium hypothesis in modeling hydrogen thermal desorption spectra. ISIJ Int 2009;49(12):1907-13.

[33] Ebihara K, Kaburaki H. Numerical modeling of thermal desorption spectra of hydrogen: a review of thermal desorption models. ISIJ Int 2012;52(2):181-6.

[34] Hurley C, Jambon F, Martin F, Marchetti L, Chêne J, Blanc C, et al. An in-depth study of the interactions between hydrogen and microstructural defects in Fe and Ni-based alloys through thermal desorption spectroscopy (TDS) and numerical simulation. In: OCAS, editor. Steelyhydrogen 2nd international conference on steel and hydrogenvol. 1. OCAS; 2014.

[35] Ebihara K, Kaburaki H, Takai K. Numerical evaluation of the Choo and Lee's method for calculating hydrogen detrapping activation energies. In: Somerday BP, Sofronis P, editors. International hydrogen conference : hydrogen-materials interactions, ASME; 2012. p. 553-61.

[36] Kirchheim R. Monte-carlo simulations of interstitial diffusion and trapping-i. one type of traps and dislocations. Acta Metall 1987;35(2):271-80.

[37] Turnbull A, Carroll M, Ferriss D. Analysis of hydrogen diffusion and trapping in a 13\% chromium martensitic stainless steel. Acta Metall 1988;37(7):2039-46. 